\title{
Venereal disease: Its place in health education in schools
}

\author{
S. J. MCGUFFIN \\ From Stranmillis College, Belfast
}

SUMMARY The paper reports the findings concerning venereal diseases and contraception in several surveys conducted into health education in Northern Ireland. The evidence shows that there is little instruction and discussion of these subjects, either at home or at school, but that teenagers are divided in their attitudes, some desiring information while others are apathetic. The need for well informed teenagers willing to make responsible decisions is stressed and reference is made to one curriculum development project producing materials in this field.

\section{Introduction}

Four surveys (McGuffin, 1976a,b, 1977) have been conducted recently into aspects of health education in Northern Ireland. One surveyed current practice in secondary schools, another inquired into the attitudes of teachers at these schools, the third surveyed the attitudes of pupils in their last year of compulsory schooling (that is $15+$ ), and, the fourth, the attitudes of their parents. In each case, venereal diseases and contraception were included among the topics under investigation.

\section{Methods}

All the surveys were conducted by questionnaire.

The principals of all 255 grammar and secondary (intermediate) schools were sent questionnaires in March 1975. Twenty-five aspects of health were listed and principals were asked which of these were taught in the school, at which age, and the method of teaching.

A cross-section sample of 500 teachers in all secondary schools covering the major subject areas were asked which of the same aspects they felt should be included in the curriculum, and which topics did they feel their subject could contribute before the pupils reached school leaving age $(16+)$.

It was planned to survey the attitude of parents of fifthformers $(15+)$ in a small cross-section sample of schools by asking these parents to complete a

Address for reprints: S. J. McGuffin, Stranmillis College, Belfas BT9 5DY

Received for publication 11 March 1977 short questionnaire. The main question was: Had the 12 topics listed been discussed at home with the fifthformer concerned and did the parents approve of the topics being discussed at school before the pupil reached the minimum leaving age ? For this investigation, a stratified sample of 10 schools was drawn with a reserve list of schools of corresponding type. Six of the schools were Protestant, and five first choice and the one second choice school agreed to participate. None of the eight Roman Catholic schools invited was prepared to co-operate. The one original Protestant school which declined explained that there were particular difficulties in the area in which pupils lived, but no reason was given by any of the Roman Catholic schools. It can only be surmised that the inclusion of contraception at least contributed to the refusals.

A similar plan was devised for the survey of pupils' attitudes. The questionnaire listed the same 12 topics as those given to parents, the pupils being asked if the topics had been discussed at home, whether they had been taught at school, and, if not, would they like to have been taught about them at school. Another cross-section sample of 10 schools was drawn and the principals were asked to allow the questionnaire to be distributed to all members of the fifth form. Eight schools agreed to take part, five being Protestant and three Roman Catholic.

\section{Results}

In the current practice survey, only 70 of the 255 schools $(27.4 \%)$ replied, probably because of the inconvenient time at which the questionnaire was sent-the last fortnight of the Hilary ierm. Venereal 
diseases and contraception were included in the curriculum of $55 \%$ of the 70 schools that completed the questionnaire. Both subjects were taught to pupils in fifth and sixth forms (14 to 15 year-olds) in about $40 \%$ of the schools, and to sixthformers $(16+)$ in about $20 \%$ of the schools. Contraception was discussed mainly with religious studies or biology, while venereal diseases were covered either by biology teachers or in health education courses in which health visitors participated. Although all pupils are obliged to take religious studies (unless their parents conscientiously object), the study of biology and/or health education beyond third form is generally a matter of choice so that many pupils probably do not discuss these topics at all. In fact the replies indicated that only in one-quarter of schools did all boys learn about these topics and in only one-third of schools were they included in the curriculum for girls. These are probably the schools in which the religious studies department was responsible for the teaching.

Replies were received from 240 of the 500 teachers $(48.0 \%)$ in the second survey. Of these $157(65.4 \%)$ approved the inclusion of venereal diseases, while $54(22.5 \%)$ disapproved. The figures for contraception were $136(56.7 \%)$ approved and $69(28.8 \%)$ di approved. In each case there were a numbe: who offered no opinion. Of the 25 topics listed, venereal disease ranks 21 st and contraception 24th in order 0 degree of approval. The attitudes of teachers in different types of schools were compared and the only statistically significant difference was in respect of contraception between teachers in controlled and in maintained/voluntary schools. In controlled schools $67.4 \%$ approved compared with $49.5 \%$ in maintained/voluntary schools $\left(\chi^{2}=6 \cdot 22, P<0.01\right)$. In Northern Ireland most controlled schools have Protestant pupils and teachers, in the maintained/ voluntary sector there are many Protestant (chiefly grammar) schools, while all the Roman Catholic schools are included in this category. It seems that the attitude of the Roman Catholic Church to contraception is responsible for this difference.

In respect of venereal diseases, $58.3 \%$ teachers of religious studies, $53.7 \%$ of biology, and $45.5 \%$ teachers of general sciences felt they could con ribute; for contraception the figures were: religious studies $41.7 \%$, home economics $37.5 \%$, and biology $37.5 \%$. It was interesting to note that 33 teachers felt their subject could contribute to the teaching of contraception to pupils below 16 years of age, but 16 thought that the subject should be taught to sixthformers only. A similar but less pronounced situation applied to venereal diseases, where 36 were prepared to teach the subject to those under 16 and seven only to those over 16 .
Questionnaires were sent to 496 Protestant parents, of whom $247(49.8 \%)$ replied. Of these 91 $(36.8 \%)$ claimed to have discussed contraception and venereal diseases with their teenage children. This indicated that of the 12 topics listed these are the two discussed by fewest parents. However, $55.8 \%$ would like contraception and $66.3 \%$ would like venereal diseases included in the health education curriculum at school before pupils reach $16+$, while the number who disapproved was $17.0 \%$ for contraception and $8.5 \%$ fcr venereal diseases. The comparison between the extent to which the topics were discussed at home with boys and with girls showed that the two aspects under consideration were the only two where the difference was statistically significant at the $1 \%$ level, in each case discussion taking place with girls to a greater extent than with boys. There was a strong indication that parents of grammar schools pupils discussed health topics generally to a greater extent than parents of secondary school pupils and this applied to the topics being considered.

Altogether, 733 fifthformers were present when the questionnaire was administered. Analyses of replies were carried out for four groups, categorised by sex and religion, but the overall patterns indicated by these were similar for all the groups. While these topics were discussed in few homes and taught in few schools, they headed the list of topics which pupils wished to be taught in schools. On average about $46 \%$ of pupils requested teaching on venereal diseases (ranking first among the requests for each group) and about $37 \%$ wanted to be taught about contraception (ranking second for each group). However, nearly $30 \%$ showed no interest in venereal diseases, and just over $25 \%$ expressed no interest in contraception.

The significant difference between the groups was that contraception was discussed with a greater number of girls than with boys in both Protestant and Roman Catholic homes (Protestant girls 27\%; boys $15.1 \% \chi^{2}=13.3, P<0.01$; Roman Catholic girls $29.5 \%$; boys $\left.12.4 \% \chi^{2}=7 \cdot 15, \mathrm{P}<0.01\right)$ and in Protestant schools more girls $(47 \cdot 4 \%)$ were taught than boys $(34.9 \%)\left(\chi^{2}=489, P<0.05\right)$. In Roman Catholic schools, more boys $(22.9 \%)$ than girls $(11.5 \%)$ claimed to be taught about venereal diseases $\left(\%^{2}=9.23, \mathrm{P}<0.01\right)$ but more girls $(35.1 \%)$ than boys $(13.1 \%)$ requested teaching on the subject $\left(\varkappa^{2}=4.39, \mathrm{P}<0.05\right)$.

\section{Discussion}

The impression from all the surveys is that there is little systematic discussion or instruction on matters relating to sexual behaviour. Many young people 
do not receive any information or guidance while at school; few teachers feel competent to deal with these topics; many parents avoid the subject at home, but some would not object to instruction being given in school. Among the young people themselves there was a fair amount of apathy, while some showed positive interest and a desire for guidance. It is clear that the current position, at least in Northern Ireland, is no different from that in Great Britain some years ago. Second among the seven reasons listed by one writer (Catterall, 1972) for the increase in venereal diseases in the 1960 s was ignorance of the subject. He claimed that sexual education was totally inadequate and that many parents found it difficult to discuss sexual matters and were often unable to give accurate facts about venereal disease. He stated that steps must be taken to improve the presentation of information in a form acceptable to adolescents and referred to the widely diffused education about sexual matters, venereal diseases, and contraception. Specifically on contraception, the argument for full information was well stated by Brook (1971) who claimed that the more sexual enlightenment there was, the greater the prospect of responsible sexual behaviour. He stressed that one of the educational aims of each secondary school must be to teach that there should be no sexual intercourse without mutual love and respect and no sexual intercourse without use of contraceptives unless the two people concerned have decided they want a child. Schools should not lay down general prohibitions, but should not opt out of the situation, although issues are delicate and the teaching is demanding.

There is an additional dilemma. The age of consent is 16 years, which coincides approximately with school leaving age. If instruction and advice are not given before teenagers leave school, they are unlikely to receive it in any systematic way elsewhere. The Health Education Council (1977) in its new leaflet pack on sexually transmitted infections warns that, if parts of it are distributed to pupils and taken home, parental complaints may follow. The new pack, which is primarily intended for use in clinics, will certainly provide accurate information for those who go there, probably when they fear they have contracted such a disease, but it will not do much in the field of preventive measures. Much of it may, however, prove useful to teachers of the sixth form, in cases where pupils remain at school beyond the minimum leaving age. Future help in this work will also be available from the Health Education Council Project (McPhail, 1974) which is planning to provide materials to assist teachers with these and similar problems, using discussion techniques. A set of stimulus work cards describing situations which teenagers find intriguing or difficult has been produced, the aim being to move from interest and involvement-through communication, understanding, and optimism - to a fuller, and more rewarding life.

It is to be hoped that schools will face the responsibilities in this difficult field and will find it possible to provide all pupils with an opportunity to learn about and discuss these problems, so that a more accurately informed and responsible society may result.

\section{References}

Brook, C. (1971). Should we teach contraception in schools? Where, 62, 310-311.

Catterall, R. D. (1972). Adolescents and VD. Where, 69, 133-138.

Health Education Council (1977). Sexually transmitted infectionsnew resources available. Schools Bulletin, 7, 3.

McGuffin, S. J. (1976a). Health Education in Northern Ireland Schools, limited edition. Northern Ireland Schools Curriculum Committee: Belfast. (Copies in Health Education Council, 78 New Oxford Street, London, WC1A 1AH).

McGuffin, S. J. (1976b). Health education in Northern Ireland-a survey of current practice in post-primary schools. Journal of the Institute of Health Education, 14, 20-26.

McGuffin, S. J. (1977). What Northern Ireland teachers think about health education. Journal of the Institute of Health Education (In press).

McPhail, P. (1974). The Health Education Council's project. Ideas, 29, 109. 